\title{
Los primeros intentos para documentar la corrupción en México: los casos Pemexgate y de los Amigos de Fox
}

\author{
Córdova, Lorenzo y Ciro Murayama (2006), ElecCiones, dinero \\ y corrupción, PemeXgate y los Amigos de Fox, Cal y Arena, \\ MÉXICO, ISBN: 968-7711-65-5.
}

El libro que se reseña es un esfuerzo muy detallado por documentar uno de los sucesos más relevantes de la vida política contemporánea de México: la indagación por parte del Instituto Federal Electoral (IFE) y el Tribunal Electoral del Poder Judicial de la Federación, sobre el llamado Pemexgate y la asociación civil denominada Amigos de Fox.

El texto intenta abarcar muchas de las aristas de ambos casos. Los autores relatan y desentrañan cada etapa de la investigación y los problemas legales y logísticos que enfrentó una investigación que cuestionaba el ingreso ilícito de dinero a las campañas presidenciales de los candidatos de los partidos Acción Nacional (PAN) y Revolucionario Institucional (PRI), en el año 2000. Se trataba pues, de la primera vez que en México se echaban a andar, con seriedad y responsabilidad, los mecanismos de fiscalización de los gastos e ingresos de los partidos políticos, contemplados desde 1996 en el Código Federal de Instituciones y Procedimientos Electorales (Cofipe).

La pormenorizada descripción de cada paso que dieron estas instituciones, con el fin de establecer claramente las responsabilidades sobre los ominosos desvíos de fondos hacia el PRI y el PAN, permite al lector darse una idea de los alcances de la corrupción político-electoral en México. Así, el relato, más allá de sus circunstancias particulares, se convierte en un pretexto para preguntarse en dónde estamos parados en México con respecto al proceso de democratización iniciado a fines de los años ochenta. También nos permite cuestionarnos acerca de con qué tipo de partidos políticos contamos, qué sistema de partidos estamos construyendo, qué clase de ciudadano se está formando y, en especial, cuáles son las reformas que de manera urgente requiere la legislación electoral en muchas materias, pero en particular en el ámbito de la fiscalización. 
Pero aún más, el libro puede ser un pretexto para pensar en el gran tema de fondo: la corrupción política en las sociedades contemporáneas; lo cual merece una profunda reflexión. No únicamente debemos ahondar en el asunto por la introducción de dinero ilícito en las campañas electorales; pues estos hechos son sólo la punta de un iceberg que habría que desmontar con más elementos analíticos. De entrada, en esta obra se asume muy mecánicamente la relación entre dinero, elecciones y medios masivos, relación que también comparten muchos estudiosos del tema (Zovatto, 2003; Nohlen et al., 1998; Alcocer, 1993; Gruenberg, 2000; Woldenberg, 1999 y 2003), por lo que nos parece que hay que examinar el tema con más detenimiento.

Brevemente proponemos los siguientes puntos para la reflexión. En primer lugar, se considera sin mayor cuestionamiento que para ganar una elección se requiere dinero, y que además las victorias electorales tienen que pasar necesariamente por el ámbito de los medios masivos de comunicación. Aún más, dice Woldelberg (2003), el financiamiento público a los partidos políticos y sus campañas electorales ha sido así en muchos países democráticos y no parece haber remedio a la vista. Los políticos necesitan dinero para ganar votos y los medios son los que más influyen en ello. Es necesario estudiar esa relación tan automática en virtud de que, si asumimos tales verdades, estaremos aceptando que entre más dinero, más seguro será el triunfo electoral, y que mientras mayor sea la penetración vía medios masivos, más posibilidades tienen los partidos políticos de ingresar a los puestos de elección popular. Por tanto, los partidos se ven obligados a obtener dinero a toda costa y en cualesquier ámbito, lo que ha constituido precisamente la antesala de la corrupción. Mientras que de forma paralela los medios de comunicación, sobre todo privados, no solo se enriquecen inusitadamente, sino que en el fondo se han convertido en los verdaderos jefes de las campañas electorales. Éstas son dos de las consecuencias perversas de tomar como irrefutables los supuestos antes mencionados.

En segundo lugar tenemos otra consecuencia: el alejamiento ciudadano de la política, manifestado en el aumento de la desconfianza en las instituciones democráticas y en la escasa legitimidad de los gobiernos, en principio de origen electoral limpio. Todo ello documentado por los sondeos de cultura política que hacen desde las organizaciones gubernamentales (Encuesta Nacional sobre Cultura Política 
y Prácticas Ciudadanas, Encup) y las comerciales (Mitofski), hasta las de orden académico (Freedom House, Latinobarómetro, LAPOP). ${ }^{1}$ El ciudadano que observa una abierta relación entre el dinero y sus representantes o que es abrumado por una propaganda electoral que parece no tener fin, lejos de aproximarse e interesarse en la vida política, busca escapar de ella. No son gratuitos los bajos índices de votación en la primera década de este siglo, por ejemplo en América Latina (Alcántara, 2001) y tampoco sorprende la precariedad del capital social (Putnam, 1993) en la misma región en general, y en México en particular.

En tercer lugar, considerar dicha relación tal cual constituye un campo fértil para eludir el compromiso ciudadano y contribuye a acrecentar la intolerancia; ideas que tendrían que estar echando raíz en sociedades provenientes de regímenes autoritarios. Como dice Nolhen (2006), pasada la fase de transición, se requiere la "legitimidad de salida".

Por todo lo anterior, aceptar que la triple relación entre dinero, elecciones y medios es insustituible merece discutirse. Más allá de las consecuencias prácticas señaladas, tenemos a la vista un empobrecimiento de la vida política, o como dice Zobatto, “...una pérdida progresiva del prestigio de la política” (2003: 37).

Consideramos que los supuestos del libro reseñado, compartidos en la literatura ya referida, deben ser ampliamente revisados. Pues de otro modo, las sociedades contemporáneas que aspiran a la democracia se están viendo condenadas a padecer las consecuencias de una relación perversa entre elecciones, dinero y medios. Al menos valdría la pena preguntarse si existen otros modos de hacer campañas políticas que no requieran de los medios o si éstos se pueden acotar en materia de propaganda electoral. O si la ciudadanía merece un bombardeo electoral, o si tal vez prefiriese algo de mayor calidad y menos espectacular. O dicho de otro modo, si le damos a la vida política un rango mayor evitando así el alto costo de entrar al juego de los compromisos y los intereses privados. Éstas son las cuestiones de fondo de la corrupción político-electoral.

Quizá la mayor debilidad de este libro, no obstante su calidad documental, es que no se acerca a estos cuestionamientos. Sin embargo, aborda con más acierto las circunstancias particulares de la corrupción en los casos del Pemexgate y de los Amigos de

\footnotetext{
${ }^{1}$ Latin American Public Opinion Project (LAPOP) es una organización que lleva a cabo estudios de opinión para América Latina y cuya sede se encuentra en la Universidad de Vanderbilt (http://sitemason.vanderbilt.edu/lapop/links).
} 
Fox -como hechos de execrable violación de las normas electorales nacionales- que se presentaron después de las elecciones del 2000, que paradójicamente, marcaron el fin del sistema hegemónico y el principio de la era democrática.

En el Pemexgate los autores nos muestran un hecho contundente: hubo desvío ilegal de fondos hacia el PRI. Una pregunta se asoma: ¿por qué después de casi siete décadas de gobierno ininterrumpido, el PRI apeló a la violación flagrante de todas las normas éticas y legales con el propósito de mantenerse en el poder? ¿Esto todavía es válido en una democracia incipiente? Parece que en México ya no lo es, pues el PRI además de hacerse acreedor a una multa significativa -la más drástica conocida en la historia del mundo a un partido político, dicen nuestros autores-, se fue ganando el descrédito paulatino de su militancia, sus simpatizantes y del votante común. El PRI de todas maneras perdió. Esto puede ser una evidencia sugerente de que, en mi percepción, estamos forjando una ciudadanía más atenta y menos manipulable. Que el dispendio en campaña no es garantía de triunfo electoral, que el ciudadano quizá ya no es tan proclive al soborno burdo de antaño. En otros términos y aludiendo a lo expuesto antes, que la relación entre dinero y elecciones no es tan clara.

Sin embargo, el caso de los Amigos de Fox nos vuelve a referir que hay un efecto importante en la votación cuando se cuenta con recursos desmedidos para obtener el favor popular. Y otra vez estamos ante una ciudadanía todavía muy influenciada por la mercadotecnia abierta y agresiva para comprar el voto. Aspectos muy cercanos a lo que Anthony Downs (1957) llama el costobeneficio del voto en las democracias.

Además, el libro reseñado nos permite observar que los partidos políticos en México han entrado al juego de obtener a toda costa más dinero para sus campañas y con ello, eventualmente, arribar al poder. Los propios partidos perciben la relación dinero-poder como central para sus propósitos. Son -dicen los autores- “...seres humanos cargados de intereses y no arcángeles que jamás caerán en la tentación” (p. 17).

A lo largo del texto también resalta el resumen de los debates en el Consejo General del IFE en los casos analizados. Llama la atención la argumentación propiamente técnica, legal y política que los consejeros hicieron en defensa de la legalidad en ambos procesos, al lado de la defensa francamente cínica de los partidos para salvaguardar sus intereses, de acuerdo con las indagaciones de nuestros autores. 
Una frase enmarca la sentencia política de los consejeros electorales para actuar frente a un documentado desvío ilegal de recursos hacia un partido político. Alonso Lujambio dice que no actuar "supondría la institucionalización de la impunidad" (p. 83). Posición apuntalada todavía con más precisión jurídica cuando el Tribunal emitió la sentencia y la sanción bajo los instrumentos del denominado "levantamiento del velo" y de la "culpa in vigilando" (pp. 107-108).

Pero el caso de los Amigos de Fox se agrega al relato de los autores. Con sus particularidades, el asunto final era el mismo, manejo ilícito de fondos para el financiamiento de partidos y campañas políticas. Aquí la diferencia era que el grupo denominado Amigos de Fox llevó a cabo una intrincada red de triangulaciones financieras que hacían sumamente complicada la averiguación del ilícito. Contando para ello con un conjunto de lagunas y omisiones que la legislación electoral tiene -todavía hoy- en materia de fiscalización. Ardua e intrincada tarea del IFE, según documentan Córdova y Murayama.

Un problema era evidente, el secreto bancario que protegía las transacciones de particulares, luego demostró ser parte de la red que financiaba los partidos Acción Nacional y Verde Ecologista.

El resultado a la larga, y luego de muchos pormenores jurídicos, fue la posibilidad de que el IFE se erigiese en autoridad hacendaria con los partidos políticos. Éste fue un logro de enorme trascendencia, no sólo para el Instituto, máxima autoridad en materia electoral, sino para el desarrollo de un sistema de partidos regulado y transparente. En virtud de este precedente se anuló el secreto bancario para la fiscalización de los partidos políticos, esencial para desentrañar la corrupción electoral en México como señalan atinadamente los autores.

La respuesta del PAN -según nos describen- fue de abierta simulación al negar toda responsabilidad y vínculo sobre la actuación financiera de Amigos de Fox. Era evidente que el argumento no se sostenía, la campaña presidencial de Vicente Fox fue financiada por una red ilegal de transferencias hacia el PAN, o algunas veces sin su intervención. Culpa in vigilando aplicó posteriormente el tribunal y sancionó.

No nos extendemos más en la rica lectura del texto que se reseña, pues resultará interesante para el lector conocer con detalle los alegatos de fiscalización de los partidos políticos así como la construcción y reconstrucción de las bases institucionales para llevarla a buen puerto. Es una parte descriptiva muy rica, pero débil en cuanto a su fundamentación analítica. 
Finalmente el libro invita a pensar en las necesarias y urgentes reformas a la legislación electoral mexicana. La lista es larga: reformas sobre los ingresos y egresos de los partidos; nuevas fórmulas de financiamiento público (es más, urge discutir si éste debe continuar y cómo); reformas en los gastos (o mejor dicho, ofensivos dispendios) de las campañas y regulación de las precampañas y su duración (obviamente su reducción); discutir tiempos y gastos en radio y televisión (grandes ganadoras de la política en México); y otros más como remover el secreto fiscal para el IFE o el intercambio de información entre autoridades electorales, etc. Sobre algunos de estos temas, como lo hemos expuesto líneas arriba, sería deseable comenzar por cuestionar las bases del financiamiento público a los partidos políticos en México, ya que, tal y como se encuentra en la actualidad, no parece que resuelva de fondo el riesgo siempre latente de la corrupción.

Por último, habría que resaltar que, más allá de los datos y hechos que el libro ofrece de manera muy descriptiva, su lectura invita a reflexionar con más seriedad en la relación entre dinero y poder y en sus consecuencias para el horizonte de la democratización en marcha, por ejemplo en América Latina. Para esta región, por desgracia, la literatura que aborda el fenómeno se ha centrado sobre todo en los casos de corrupción de mayor escándalo político, como el de Collor de Mello, Fujimori o Carlos Andres Pérez. Falta todavía abordar de manera más seria y fundamentada el caso de los medios de comunicación.

En general, el libro es un documento de consulta muy serio para conocer los pormenores de los casos Pemexgate y Amigos de Fox; sin embargo, deja pendiente el análisis de fondo para tratar el asunto de la corrupción política en las sociedades contemporáneas.

\section{Bibliografía}

Alcántara, Manuel (2001), Partidos políticos en América Latina, Fondo de Cultura Económica-Instituto Federal Electoral, México.

Alcocer, Jorge (comp.) (1993), Dinero y partidos: propuestas para regular los ingresos y los gastos de los partidos políticos, CEPNA-Nuevo Horizonte, México.

Downs, Anthony (1957), An Economic Theory of Democracy, Harper and Row, Nueva York. 
Gruenberg, Christian (2000), Monitoring the Financing of Political Campaigns from the Civil Society, Poder Ciudadano, Transparencia, Buenos Aires.

Lujambio, Alonso (2003) “México”, en Manuel Carrillo Alonso Lunjambio, Carlos Navarro y Daniel Zobatto (comps.), Dinero y contienda político electoral, el reto de la democracia, Fondo de Cultura Económica, México.

Nolhen, Dieter (2006), "Instituciones y cultura política", conferencia ofrecida en el Instituto Electoral del Estado de México, 14 de febrero de 2007.

Nohlen, Dieter, Silvia Picado y Daniel Zobatto (comps.) (1998), Tratado de derecho electoral comparado en América Latina, IIDH/CAPEL-Universidad de Heidelberg-Tribunal Electoral del Poder Judicial de la Federación-Instituto Federal Electoral-Fondo de Cultura Económica, México.

Putnam, Robert (1993) Making democracy work: civil traditions in modern Italy, Princeton University Press, Nueva Jersey.

Woldelberg, José (1999), La mecánica del cambio político en México, Cal y Arena, México.

Woldelberg, José (2003), "Relevancia y actualidad de la contienda político-electoral", en Manuel Carrillo, Alonso Lujambio, Carlos Navarro y Daniel Zovatto (comps.), Dinero y contienda político electoral, el reto de la democracia, Fondo de Cultura Económica, México.

Zovatto, Daniel (2003), “América Latina”, en Manuel Carrillo, Alonso Lujambio, Carlos Navarro y Daniel Zovatto (comps.), Dinero y Contienda Político Electoral, el reto de la democracia, Fondo de Cultura Económica, México.

Recibido: 20 de febrero de 2007. Aprobado: 21 de febrero de 2007.

Laura Leticia Heras-Gómez es doctora en ciencias sociales. Actualmente es Directora de la Facultad de Ciencias Políticas y Administración Pública, de la Universidad Autónoma del Estado de México. Es miembro del Sistema Nacional de Investigadores, 
nivel I y es perfil Promep. Su línea de investigación actual se centra en cultura y participación política, política comparada, estudios sobre democratización. Sus publicaciones más recientes son: "Más allá del PRD: avances en la investigación sobre la izquierda política mexicana", Convergencia, UAEM, 13 (42): 249-255(2006); "El estudio de la ciencia política en México y sus antecedentes en la UAEM", Espacios Públicos, FCPyAP-UAEM, 9 (17): 10-19 (2006); "Cultura política y democratización en América Latina", Revista de Ciencias Sociales (Cr), Universidad de Costa Rica, II (104): 27-37, (2004); "Participación política en México: convergencia de dos tendencias, 1982-2002", Revista Apuntes Electorales del IEEM, V (2): 86-112 (julio-septiembre, 2005); "Cultura Política el Estado del Arte contemporáneo”, en Reflexion Política, revista del Instituto de Estudios Políticos de la UNAB, Colombia, 4 (8):275291 (diciembre, 2002). 